\title{
Numerical Simulation and Experimental Investigation on Inclusion-Argon-Liquid Steel Phenomenon in RH Refining of High-Manganese and High-Aluminum Steel
}

\author{
Lifeng Chen (D), Kun Liu $\mathbb{D}^{D}$, Peng Han $\mathbb{D}^{D}$, Lianghua Feng $\mathbb{D}$, and Guangqiang Liu \\ School of Materials and Metallurgy, University of Science and Technology Liaoning, Anshan 114000, China \\ Correspondence should be addressed to Kun Liu; 1k651206@ustl.edu.cn and Peng Han; hanpeng@ustl.edu.cn
}

Received 4 June 2019; Accepted 9 August 2019; Published 12 September 2019

Academic Editor: Dongmin Yang

Copyright (c) 2019 Lifeng Chen et al. This is an open access article distributed under the Creative Commons Attribution License, which permits unrestricted use, distribution, and reproduction in any medium, provided the original work is properly cited.

\begin{abstract}
In this paper, factors influencing the inclusion removal in high-manganese and high-aluminum steel in RH refining process were studied by numerical simulations, production practice, and metallographic experiments. A mathematical model for inclusion removal was established, and the phenomenon of inclusions mixing in RH up-leg region was verified due to fluid circulation. Removal efficiency of RH circulation time $120 \mathrm{~s}$ is much better than $600 \mathrm{~s}$, and it was the lowest efficiency after $600 \mathrm{~s}$. After $600 \mathrm{~s}$ circulation time, it shall not apply in production practice. The mass concentration of inclusions in practical steel was $11.64 \%$ probability error than values obtained by numerical simulation, because the numerical simulation did not consider the problem of inclusions adsorbing to the walls of refractory materials and corrosion of refractories. This work lays the foundation for the optimization and upgrading of process technology and establishes big data for full automation of $\mathrm{RH}$ out of furnace refining.
\end{abstract}

\section{Introduction}

With the optimization of quality and process, significant progress has been made in the applications of high-manganese and high-aluminum steel. They possess excellent strength, low density, high quality, and good elongation, thereby showing utility in automobile inner plates, electrical motor rotors, marine engineering, military applications, and refrigeration materials. However, the problem of nonmetallic inclusions in metallurgical industry seriously affects the quality of high-manganese and high-aluminum steel, which leads to lower service life. With the rapid development in the steel industry, there is increasing demand for highquality steel. Researchers have found that oxide nonmetallic inclusions play an important role in the performance of clean steel [1-3]. The removal of inclusions and the control of small inclusions are important factors that directly affect the quality of steel. RH refining in steelmaking process has prominent technical advantages for smelting clean steel [4]. It is conducive to the removal of inclusions and the improvement of steel quality. Therefore, removal of inclusions in steel in $\mathrm{RH}$ refining process has been the focus of metallurgical research for several years [5-12].

Chen et al. analyzed the process of inclusion collision and growth removal, and considered the influence of gas bubbles in the formation model. However, the influence factors of inclusions adsorbing RH refractory material walls were neglected [13]. The model also did not meet the overall mass conservation of inclusions, and did not consider the distribution of inclusions in RH flow field [14]. Taking ladle as the research object, the inclusion removal in the refining process was studied using the equation model of particle number concentration. The research focused on the formation mechanism of inclusions and the distribution of gas stirring in clean steel. Wang et al. studied the crystal structure and cluster mechanism of inclusions, especially alumina [15]. However, there was no reasonable demonstration on the distribution of inclusions or a mathematical model. Since there were no detailed descriptions and explanation of inclusions, it is difficult to use their experimental conclusions to guide the process production practice $[16,17]$. Describing the $\mathrm{RH}$ flow field of inclusions and 
establishing the physical model, the mathematical model did not consider the problem of inclusions growth and collision. It also did not consider the probability error between the model establishment and production practice. Due to the shortcomings of existing models, this study uses actual production data to modify the $\mathrm{RH}$ inclusions removal model and analyzes the influence factors of RH circulation flow rate and circulation time on inclusions removal. Predicting the accuracy and reliability of $\mathrm{RH}$ inclusion removal provides theoretical guidance for process production practice.

In this paper, a mathematical model of $\mathrm{RH}$ inclusionargon-liquid steel is established in order to provide the foundation for process production by combining mathematical simulation with production practice. By determining the influence of $\mathrm{RH}$ circulation time and circulation flow rate on inclusion-argon-molten steel, the $\mathrm{RH}$ inclusions-argonmolten steel are analyzed by using the methods of numerical simulation and production practice, and the feasibility of the mathematical model is demonstrated on the basis of experimental data. The proposed method overcomes the probability error between the mathematical model and experimental data, making it more valuable for production practice. Two technical routes of numerical simulation and experimental research are used to analyze and predict the accuracy and reliability of RH inclusion removal, which provide a theoretical basis for process production practice and lay a basis for fully automated steelmaking.

\section{Model Building}

2.1. Basic Hypothesis. The hypothesis of the model is as follows.

The liquid steel is an incompressible Newtonian fluid, and its multiphase flow is unsteady. The fluctuation of liquid level in ladle top slag and vacuum chamber and the influence of temperature on other physical quantities are neglected. Inclusions nucleate into spheres instantaneously in molten steel, ignoring the effect of slag on other physical quantities. Ladle refractories and $\mathrm{RH}$ refractories set wall function. The effect of inclusions on the physical quantity of molten steel is neglected in fluid flow. When inclusions reach the molten steel level, they can be considered to be removed. Argon bubbles are assumed to have a circular $[18,19]$.

2.2. Control Equation. In the simulation, continuity equations were used to model the reference materials, as follows:

$$
\begin{aligned}
\frac{\partial \rho_{\mathrm{m}}}{\partial_{t}}+\nabla\left(\rho_{\mathrm{m}} \vec{u}_{\mathrm{m}}\right) & =0, \\
\rho_{\mathrm{m}} & =\rho_{\mathrm{g}} \alpha+(1-\alpha) \rho_{\mathrm{l}},
\end{aligned}
$$

where $\rho_{\mathrm{m}}$ refers to the average volume density, $\mathrm{kg} / \mathrm{m}^{3} ; \vec{u}_{\mathrm{m}}$ is the average mass velocity, $\mathrm{m} / \mathrm{s}$. A homogeneous flow model is used to simulate the fluid field, and the average density of gas and liquid are $\rho_{\mathrm{g}}$ and $\rho_{\mathrm{l}}$, respectively, $\mathrm{kg} / \mathrm{m}^{3} . \alpha$ is the gas fraction, \%. RH under vacuum conditions, the gas fraction is calculated as follows:

$$
\alpha_{0}=\frac{p_{\mathrm{v}}+\rho_{\mathrm{l}}\left(H-Z_{0}\right)}{P_{\mathrm{V}}+\rho_{\mathrm{L}}(H-Z)},
$$

where $H$ refers to the liquid level height of the vacuum chamber, $\mathrm{m} ; Z_{0}$ corresponds to nozzle height, $\mathrm{m}$; $Z$ refers to the height of the two-phase region, $\mathrm{m} ; P_{\mathrm{V}}$ refers to vacuum chamber pressure, $\mathrm{Pa} ; g$ refers to gravitation acceleration, $\mathrm{m} /$ $\mathrm{s}^{2}$; and $\alpha_{0}$ refers to the formula for determining the distribution of gas fraction hold up, \%.

Momentum equation:

$$
\begin{aligned}
\frac{\partial\left(\rho_{\mathrm{m}} \vec{u}_{\mathrm{m}}\right)}{\partial_{t}}+\nabla\left(\rho_{\mathrm{m}} \vec{u}_{\mathrm{m}}\right)= & -\nabla p+\nabla\left\{\left(\mu_{\mathrm{m}}+\mu_{\mathrm{Tm}}\right)\right. \\
& \left.\cdot\left[\nabla \vec{\mu}_{\mathrm{m}}+\left(\mu_{\mathrm{Tm}}\right)^{T}\right]\right\}+\rho_{\mathrm{m}} \vec{g} \\
& +\nabla \cdot\left[-\rho_{\mathrm{g}} \alpha_{\mathrm{g}} \vec{u}_{\mathrm{D}, \mathrm{g}}\right] \\
\mu_{\mathrm{m}}= & \alpha_{\mathrm{g}} \mu_{\mathrm{g}}+\alpha_{\mathrm{l}} \mu_{\mathrm{l}},
\end{aligned}
$$

where $\mu_{\mathrm{Tm}}$ refers to turbulent viscosity, Pa.s; $\mu_{\mathrm{m}}$ refers to mixing viscosity, Pa.s; $\alpha_{\mathrm{g}}$ refers to gas fraction, \%; and $\vec{u}_{\mathrm{D}, \mathrm{g}}$ refers to gas velocity vector, $\mathrm{m} / \mathrm{s}$.

Energy equation:

$$
\frac{\partial\left(\rho_{\mathrm{m}} k\right)}{\partial_{t}}+\nabla\left(\rho_{\mathrm{m}} \vec{u}_{\mathrm{m}} k\right)=\nabla\left[\frac{\mu_{\mathrm{Tm}}}{\sigma_{k}}(\nabla k)\right]+G_{k, \mathrm{~m}}-\rho_{\mathrm{m}} \varepsilon .
$$

The turbulence model constants are $\sigma_{k}$ and $\sigma_{\varepsilon} \cdot \vec{u}_{\mathrm{m}}$ refers to the mixing velocity vector, $\mathrm{m} / \mathrm{s}$. $\mathcal{E}$ refers to the turbulent energy dissipation rate, $\mathrm{m}^{2} / \mathrm{s}^{3}$.

$G_{k, \mathrm{~m}}$ is expressed as follows:

$$
G_{k, \mathrm{~m}}=\frac{\rho_{\mathrm{m}} C_{\mu}\left(k^{2} / \varepsilon\right)\left[\nabla \vec{u}_{\mathrm{m}}+\left(\nabla \vec{u}_{\mathrm{m}}\right)^{T}\right]}{\nabla \vec{u}_{\mathrm{m}}} .
$$

Turbulent flow energy dissipation equation:

$$
\frac{\partial\left(\rho_{\mathrm{m}} \varepsilon\right)}{\partial_{t}}+\nabla\left(\rho_{\mathrm{m}} \vec{u}_{\mathrm{m}} \varepsilon\right)=\nabla\left[\frac{\mu_{\mathrm{Tm}}}{\sigma_{\varepsilon}}(\nabla \varepsilon)\right]+\frac{\varepsilon}{k}\left(C_{1 \varepsilon} G_{k, \mathrm{~m}}-C_{2 \varepsilon} \rho_{\mathrm{m}} \varepsilon\right) \text {. }
$$

In the formulas (4) and (6), the values of the constants in the above turbulence models are as follows: $\sigma_{k}=1, \sigma_{\varepsilon}=1.3$, $C_{1 \varepsilon}=1.44, C_{2 \varepsilon}=1.92, C_{\mu}=0.99$. Inclusion collision growth model of density distribution function and radius of inclusions $R$ are related by the expression $f(R)=\mathrm{Ae}^{-\mathrm{BR}}$. The number density of inclusions is $N^{*}$. A and B refer to inclusion distribution factor. The mass concentration $C^{*}$ can be expressed as $[2,11,20,21]$ :

$$
N^{*}=\int_{0}^{\infty} f(R) d_{R}=\frac{A}{B} C^{*}=\int_{0}^{\infty} \frac{4}{3} \pi R^{3} d_{R}=8 \pi \frac{A}{B^{4}} .
$$

Here, there is no top slag on the liquid surface of the $\mathrm{RH}$ vacuum chamber. Inclusions adsorbed by bubbles return to the molten steel. Inclusions adsorbed by bubbles float to the liquid level of the ladle for removal. The liquid level in $\mathrm{RH}$ vacuum chamber has no ability to remove inclusions directly. The mass conservation equation of inclusion collision removal can be expressed as follows [22]: 


$$
\begin{gathered}
\frac{\partial}{\partial t}\left(\rho N^{*}\right)+\nabla\left[\rho\left(\vec{u}_{N}+\vec{u}_{1}\right) N^{*}\right]=\nabla\left(D_{\text {eff }} \nabla N^{*}\right)+S_{N}, \\
\frac{\partial}{\partial t}\left(\rho C^{*}\right)+\nabla\left[\rho\left(\vec{u}_{c}+\vec{u}_{1}\right) C^{*}\right]=\nabla\left(D_{\text {eff }} \nabla C^{*}\right)+S_{C},
\end{gathered}
$$

where $S_{N^{*}}$ refers to the decrease of the quantity density caused by the collision polymerization of inclusions, $\mathrm{m}^{-3} / \mathrm{s}$; $D_{\text {eff }}$ refers to effective diameter, $\mathrm{m}$; and $C^{*}$ refers to inclusion of bulk density, ppm. RH circulating fluid flow is mainly comprises of turbulent collision and Stokes collision.

$$
\begin{aligned}
S_{N^{*}}= & -N^{* 2} r^{* 3}\left[1.9 \frac{5 A^{*}}{6 \pi \mu_{1} r^{3}\left(4 \varepsilon / 15 \pi \nu_{1}\right)^{0.5}} 0\right]^{0.242}\left(\frac{\pi \varepsilon}{\nu_{1}}\right)^{0.5} \\
& +\frac{10 g \Delta \rho \pi r^{*}}{9 \sqrt[3]{6} \mu_{1}} .
\end{aligned}
$$

In the formula (9), $v$ is the kinematic viscosity, $\mathrm{m}^{2} / \mathrm{s} ; A^{*}$ is the constant; $\mu$ is the dynamic viscosity, Pa.s; and $r^{*}$ is the average radius of inclusions, $\mathrm{m}$. Boundary conditions ignore the surface shear stress of RH steel and vacuum chamber. The refractory materials area set wall function, the wall function node is a nonslip boundary condition, and the gradient of wall velocity component is zero. Table 1 lists the inclusions-argon-molten steel physical parameters, where we set the initial $\mathrm{RH}$ vacuum to $100 \mathrm{~Pa}$, the gas is argon, and the initial gas circulation flow is $120 \mathrm{Nm}^{3} / \mathrm{h}, 110 \mathrm{Nm}^{3} / \mathrm{h}$ and $100 \mathrm{Nm}^{3} / \mathrm{h}$. The initial mass concentration of inclusions is $187 \mathrm{ppm}$. The VOF (volume of fluid) model is used for RH fluid circulation, and the DPM (discrete phase model) is used for RH inclusions movement. Figure 1 shows the RH ladle physical model and grid model. SolidWorks is used for physical model, ICEMCFD (the integrated computer engineering and manufacturing code for computational fluid dynamics) is used for grid model, ANSYS FLUENT is imported for numerical simulation calculation, and CFDPOST is used for posttreatment analysis.

\section{Calculation Results and Analysis}

3.1. Analysis of the Impact of Inclusions. As shown in Figure 2, the mass concentration of inclusions is calculated by numerical simulation every $120 \mathrm{~s}$, with the total numerical simulation time being $600 \mathrm{~s}$. The probability error between simulated and experimental mass concentration curve of inclusions is low. The average mass concentration probability error of inclusions as determined by the mathematical model differs from the experimental data by $11.64 \%$. The numerical simulation calculates the mass concentration of inclusions every $120 \mathrm{~s}$ and compares the probability error between the corrected mass concentration curves of inclusions. The mass concentration comparison between numerical simulation and experimental data for different circulation times is listed in Table 2. For the mass concentration in the experimental and numerical simulation process, there is error for numerical simulation result. This paper analyzes the root of the probability error from the numerical simulation and process practice. This paper is based on the mathematical model of high-manganese and high-aluminum steel, and the mathematical model lays the theoretical foundation for RH full-automatic refining.

The removal of RH inclusions is analyzed by numerical simulation, the circulation time is set to $1200 \mathrm{~s}$. Figure 3 shows removal of $\mathrm{RH}$ inclusions with different circulation flow rates. The removal of inclusions in $\mathrm{RH}$ with different circulation time is compared with a circulating flow rate of $120 \mathrm{Nm}^{3} / \mathrm{h}$, where the removal efficiency of inclusion mass concentration is the highest. With the increase of circulation time, the removal efficiency of inclusions is the highest in time zone A (0s-120 s), time zone B (120s-240 s), time zone C (240s-360s), time zone D (360s-480s), time zone E (480s-600 s), and F (600s-1200s) within 600 s of circulation time. The removal efficiency of inclusions in time zone $\mathrm{F}$ $(600 \mathrm{~s}-1200 \mathrm{~s})$ decreases and achieves the lowest value. Therefore, it is not recommended to utilize the F (600 s$1200 \mathrm{~s})$ circulation time in production practice. This is further corroborated by the following three points: (a) increased RH production time leads to higher inclusions; (b) the inclusion removal efficiency is lower; and (c) since the numerical simulation does not consider the problem of inclusions adsorbing to the refractory material walls and corrosion of refractories, it exists in the process of practice.

Meanwhile, the residual amount of inclusions is influenced by many factors, among which the turbulence and buoyancy plays a dominant role. Figure 4 shows the relationship between mass concentration and circulation time with inclusions of different sizes during circulation. It can be seen that the inclusion decreases gradually with the increase of time. At the same time, small size inclusion removal efficiency is lower. In comparison, the buoyancy of large inclusions effect is larger, so it is more easy for large inclusions to enter slag. When the circulation time reaches $600 \mathrm{~s}$, buoyancy plays a dominant role in the removal of inclusions, and the diameter of inclusions also has a great impact on the removal efficiency.

RH circulation time affects the efficiency of inclusion removal and the process production. Optimization of $\mathrm{RH}$ circulation time is one of the effective methods to remove inclusions. For RH circulation times of $120 \mathrm{~s}, 360 \mathrm{~s}$, and $600 \mathrm{~s}$, mass concentration of $165 \mathrm{ppm}, 136 \mathrm{ppm}$, and $114 \mathrm{ppm}$ are observed, respectively. Figure 5 shows the inclusions removal at different circulation times and the distribution of inclusions in the fluid domain at different circulation times. From the inclusions in $\mathrm{RH}$ particle trajectory in Figure 5, it can be seen that the number of inclusions is the largest when the RH circulation time is $120 \mathrm{~s}$. This is because the circulation time is insufficient for complete removal and only a few inclusions float upwards to the molten steel level. Since there are many inclusions in the steel in the initial $120 \mathrm{~s}$, the probability of inclusions colliding, aggregating, and floating to the liquid steel level is the greatest, so the removal rate of inclusions in the initial $120 \mathrm{~s}$ is the fastest. When the RH circulation time reaches $600 \mathrm{~s}$, the amount of inclusions remaining in the steel is very small because the inclusions have enough time to float upward, 
TABLE 1: Inclusion-argon-steel liquid property parameters.

\begin{tabular}{lccc}
\hline & Steel liquid & Inclusions & Argon \\
\hline Density $\left(\mathrm{kg} / \mathrm{m}^{3}\right)$ & 7020 & 3900 & 1.6228 \\
Viscosity $(\mathrm{kg} / \mathrm{m} \cdot \mathrm{k})$ & 0.0006 & 0.02 & 0.00002135 \\
Thermal conductivity $(\mathrm{w} / \mathrm{m} \cdot \mathrm{k})$ & 34 & 1 & 0.0158 \\
$\mathrm{Cp}(\mathrm{J} / \mathrm{kg} \cdot \mathrm{k})$ & 680 & 600 & 520.64 \\
\hline
\end{tabular}

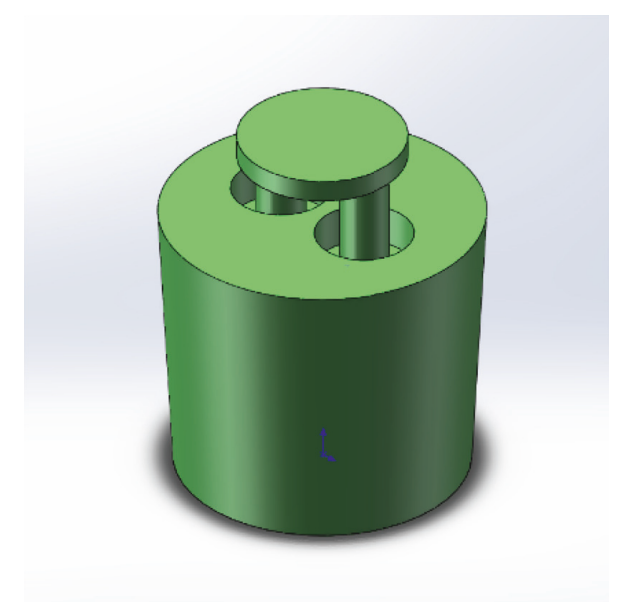

(a)

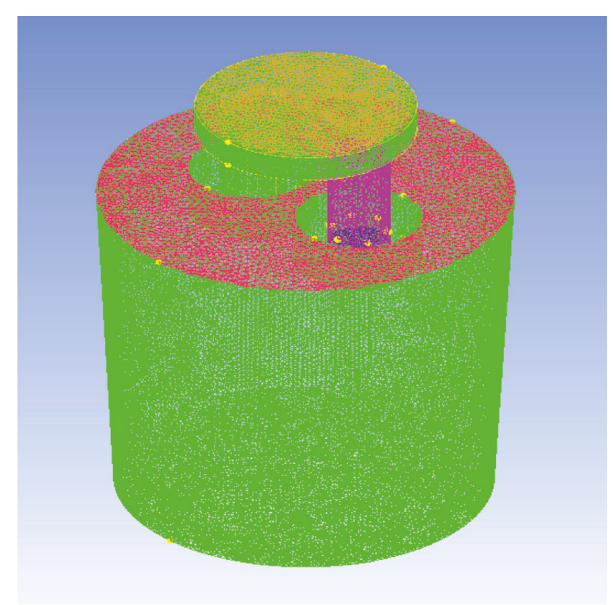

(b)

FIGURE 1: RH ladle physical model and grid model.

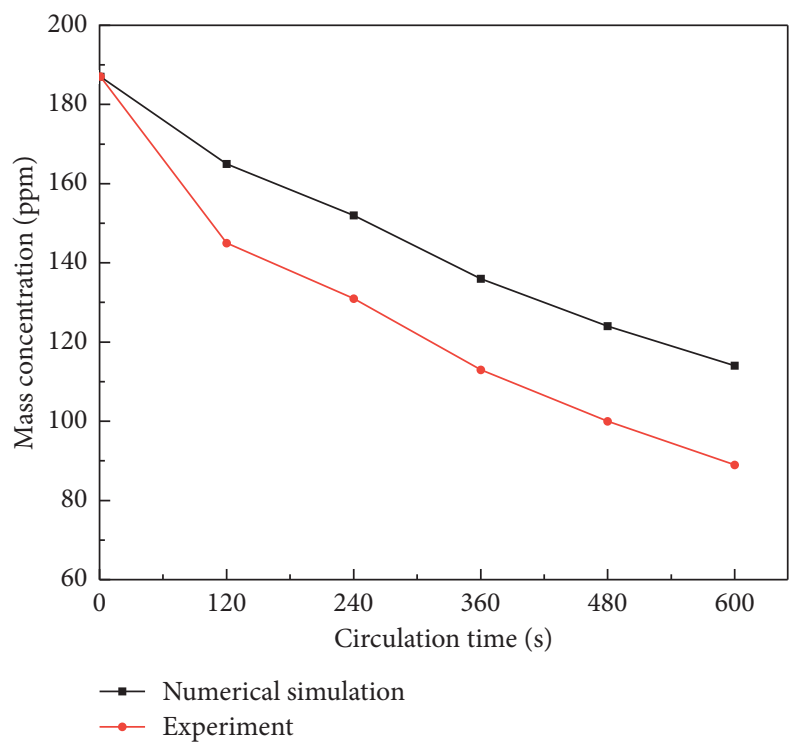

Figure 2: Numerical simulation and experiment of inclusion mass concentration.

TABLE 2: Mass concentration comparison between numerical simulation and experimental data for different circulation times.

\begin{tabular}{lccccccc}
\hline Circulation time (s) & 0 & 120 & 240 & 360 & 480 & 600 & Average value \\
\hline Numerical simulation (ppm) & 187 & 165 & 152 & 136 & 124 & 114 & 146 \\
Experiment (ppm) & 187 & 151 & 143 & 127 & 112 & 99 & 129 \\
\hline
\end{tabular}

such that they can be removed. The number of inclusions in molten steel decreases at the later stage of the circulation, which reduces the probability of inclusion collision and aggregation, which significantly reduces the removal rate of inclusions. Compared with the inclusion removal in $\mathrm{RH}$ circulation times of 120 s, 360 s, and 600 s, the efficiency of 


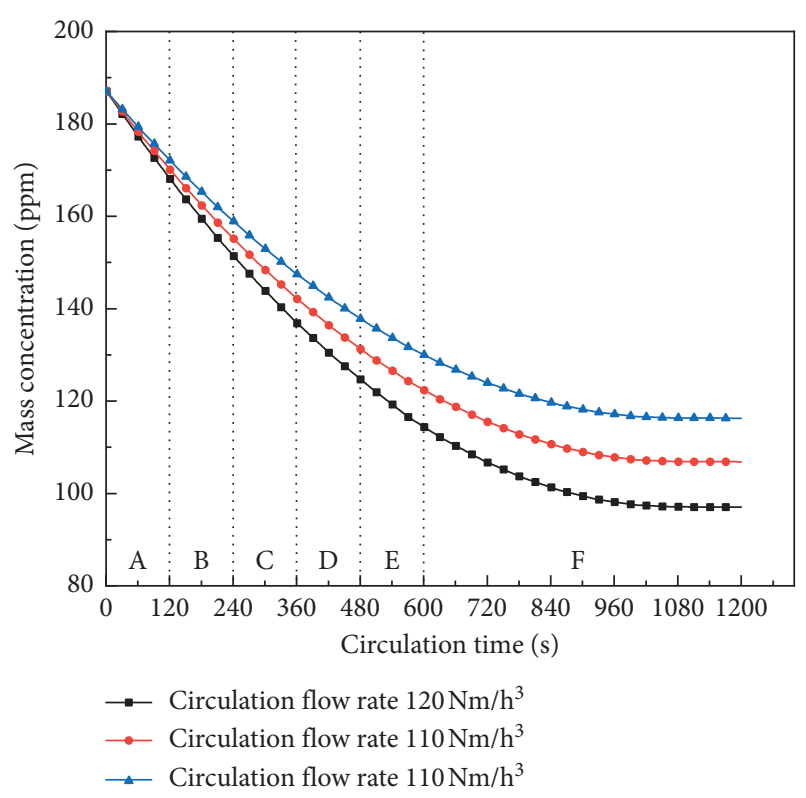

Figure 3: Removal of RH inclusions with different circulation flow rates.

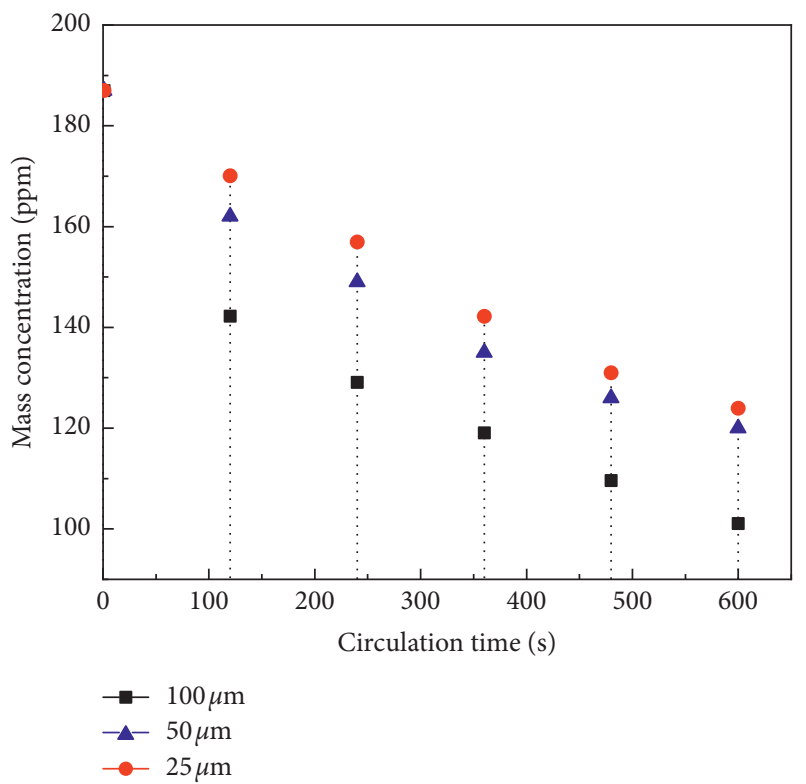

Figure 4: The residual amount of inclusions as a function of circulation time with different diameters.

inclusion removal in $\mathrm{RH}$ circulation time of $600 \mathrm{~s}$ is low. At this time, the distribution of inclusions in steel is the lowest. At the later stage of $\mathrm{RH}$ circulation, small size inclusions become a limiting factor for $\mathrm{RH}$ refining.

Figure 6 shows the inclusions in ladle particle trajectory from the fluid dynamics analysis. Argon is injected into the up-leg, which drives the molten steel due to floatation. The molten steel flows to the vacuum chamber at the up-leg and then into the ladle from the down-leg due to gravity in the vacuum chamber, thus completing one circulation flow. Due to the interaction of the inclusions-argon-molten steel, the

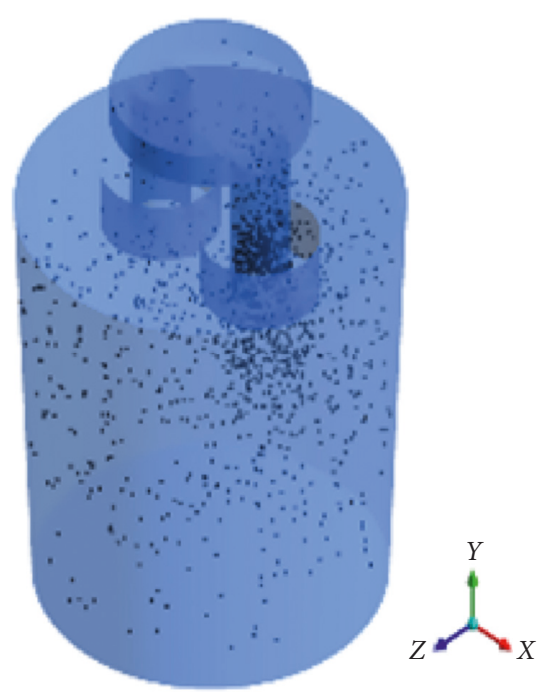

(a)

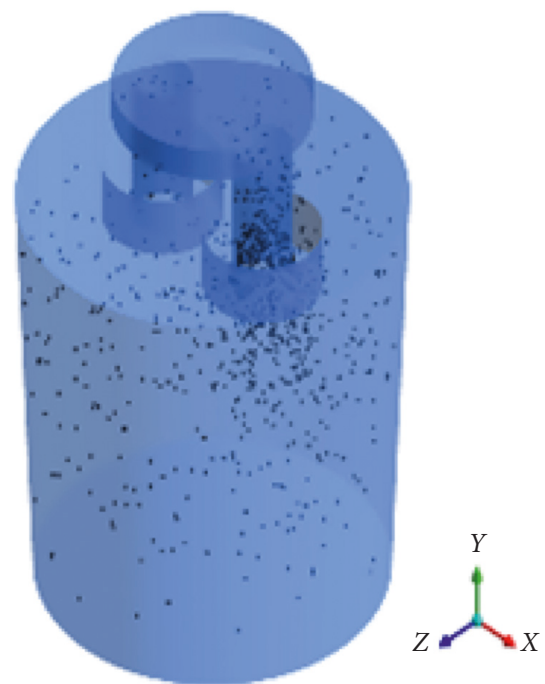

(b)

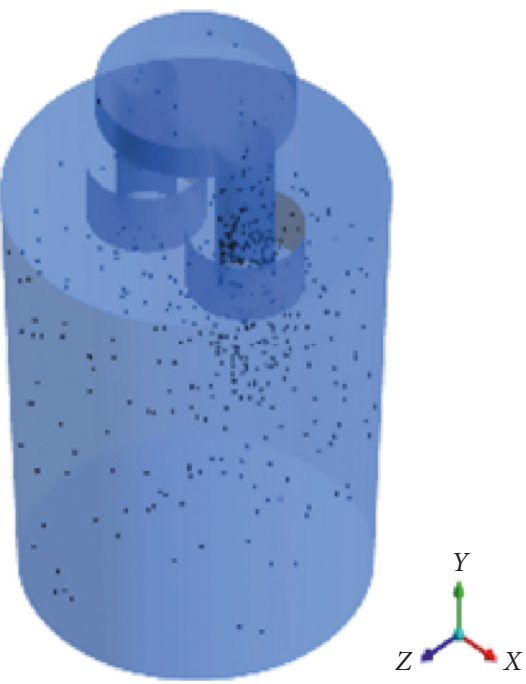

(c)

FIgURE 5: Inclusions removal at different circulation times. (a) Circulation time: 120 s. (b) Circulation time: 360 s. (c) Circulation time: $600 \mathrm{~s}$. 


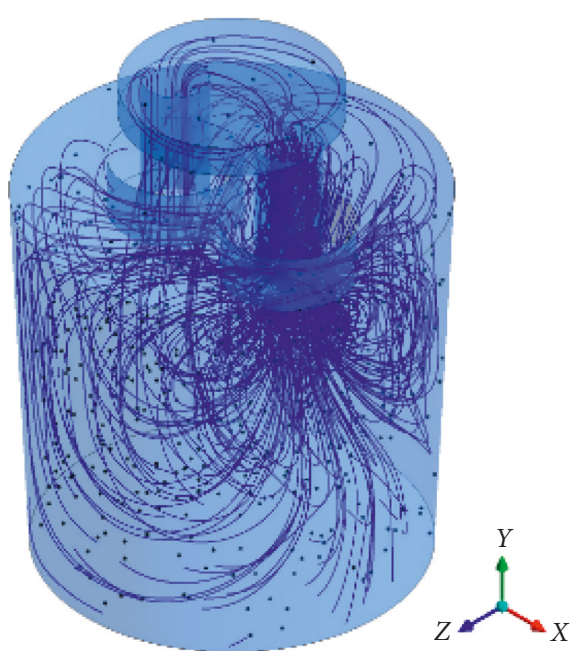

FIGURE 6: Inclusions in RH particle trajectory.
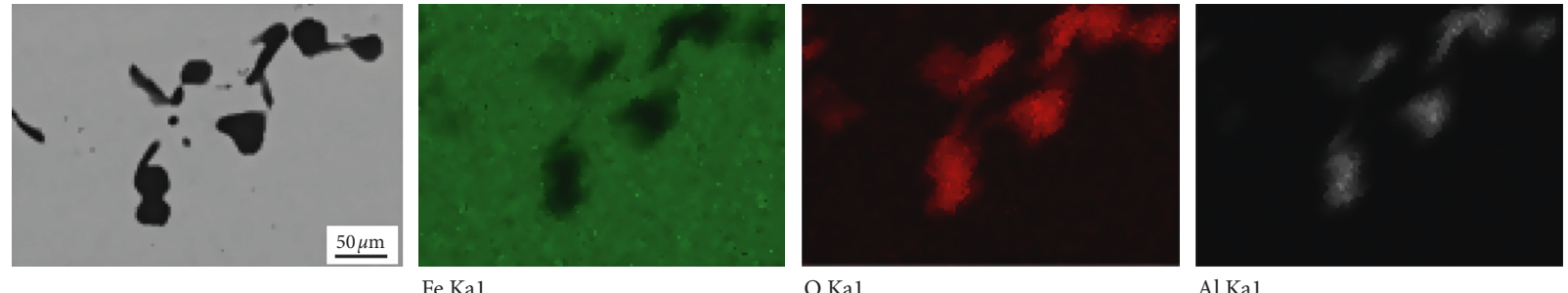

(a)
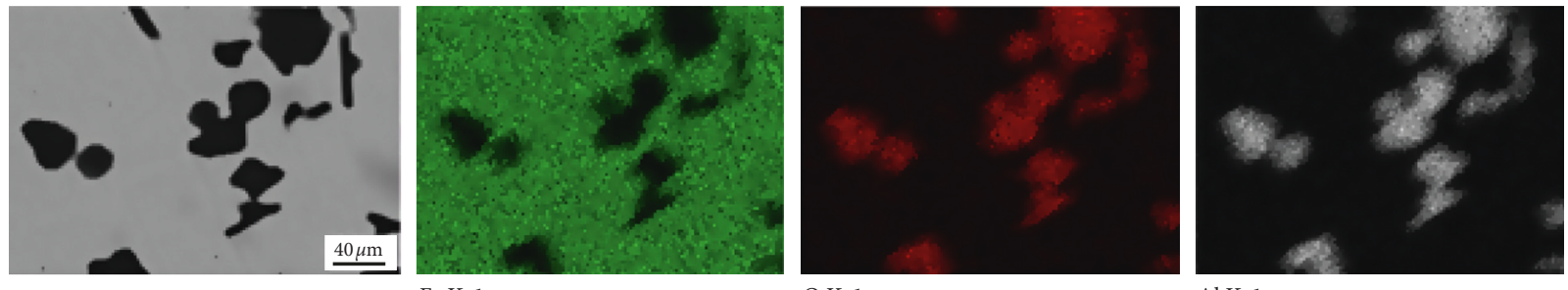

(b)
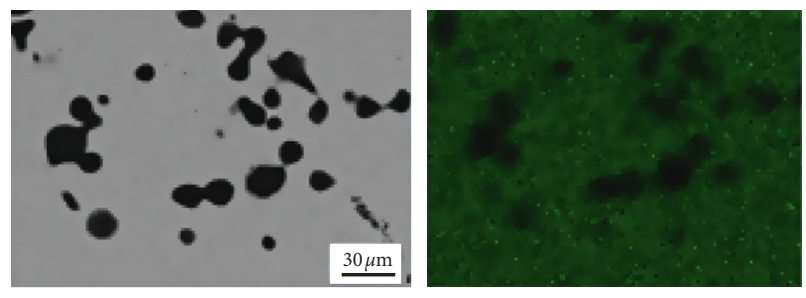

Fe Kal

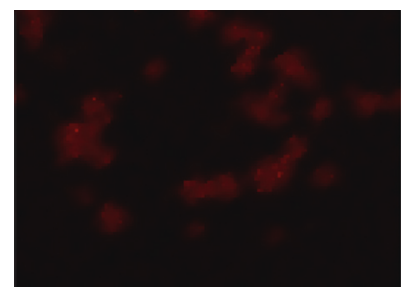

O Kal

$\mathrm{Al} \mathrm{Kal}$

(c)
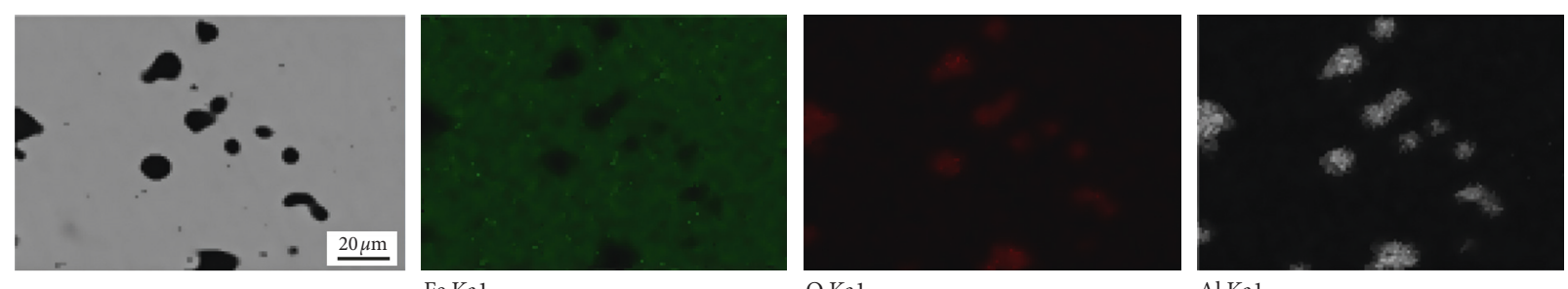

(d)

Figure 7: Continued. 

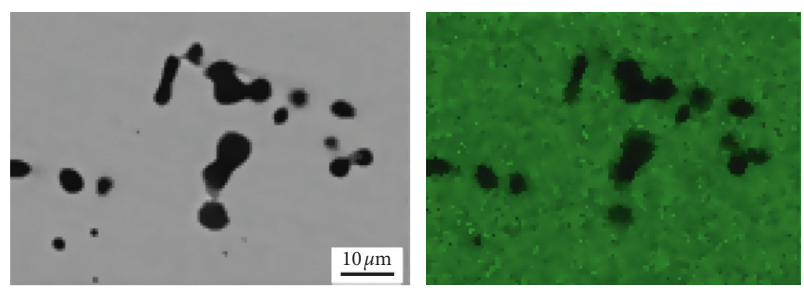

Fe Kal
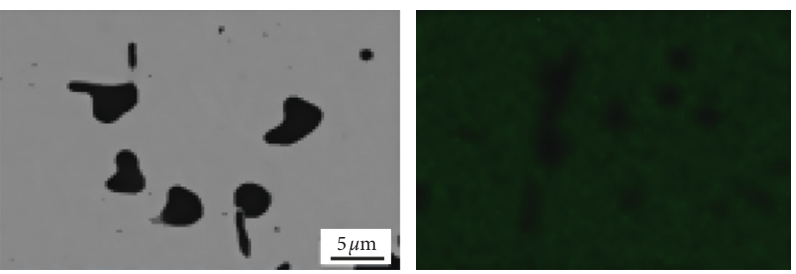

Fe Kal

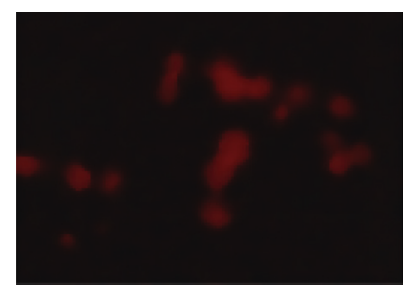

$\mathrm{O} \mathrm{Kal}$

(e)

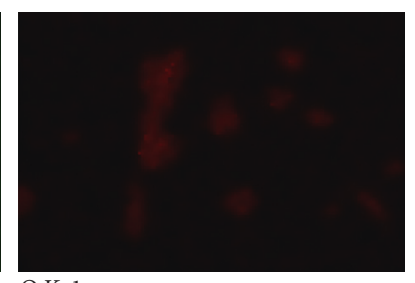

$\mathrm{O} \mathrm{Kal}$

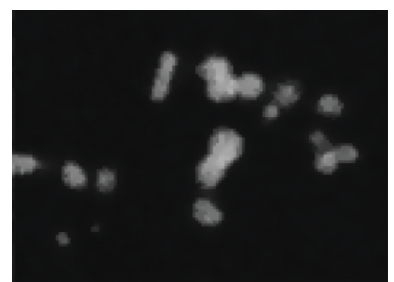

$\mathrm{Al} \mathrm{Kal}$

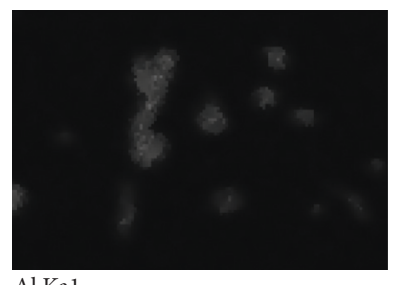

$\mathrm{Al} \mathrm{Ka1}$

(f)

Figure 7: Map scanning of inclusions in RH: (a) A0; (b) A120; (c) A240, (d) A360; (e) A480; (f) A600.

inclusions are adsorbed on the argon bubbles. The fluid flows and the argon bubbles float upward, and the inclusions are brought to the steel slag liquid surface by the argon bubbles. Differential pressure ruptures argon bubbles, and a portion of the inclusions is removed after reaching the steel liquid surface. The rest of the inclusions are rolled and mixed into the molten steel. The trajectory of inclusions in the ladle is shown in Figure 6, where the $\mathrm{RH}$ vacuum degree is $100 \mathrm{~Pa}$ and circulation flow rate is $120 \mathrm{Nm}^{3} / \mathrm{h}$. As shown in Figure 6, the inclusions are mostly distributed at the ladle liquid level and the up-leg area. This is because the inclusions follow the flow of argon and molten steel. Due to floatation, the inclusions from the up-leg flow into the vacuum chamber. Under the gravity of molten steel in the vacuum chamber, the inclusions rush into the ladle, while the $\mathrm{RH}$ vacuum chamber does not have the ability to remove the inclusions. In addition, due to the large turbulent kinetic energy of the fluid, there is entrainment in the up-leg area of $\mathrm{RH}$ suction nozzle. The entrainment area of the up-leg drives the inclusions on the steel surface to return to the molten steel, which is not conducive to the removal of inclusions. Reasonable control of turbulence intensity is the key to reduce entrainment of inclusions on the steel surface. Reducing the entrainment intensity of the up-leg is one of the methods to improve the removal efficiency of inclusions.

\subsection{Production Practice Data and Numerical Simulation} Analysis. Based on the production of high-manganese and high-aluminum steel, $\mathrm{RH}$ vacuum is set to $100 \mathrm{~Pa}$ and the circulation flow is $120 \mathrm{Nm}^{3} / \mathrm{h}$. Samples are taken every 120 seconds: A0, A120, A240, A360, A480, and A600, until a time of $600 \mathrm{~s}$ is achieved. As listed in Table 2, the difference between mass concentration of inclusions measured by numerical simulation and sample electrolytic extraction without aqueous solution is $11.64 \%$. This mass concentration probability error of inclusions occurs because the numerical simulation does not consider the problem of inclusions adsorbing to the refractory material walls and corrosion of refractories. At the later stage of $\mathrm{RH}$ circulation, small size inclusions have become the limiting link of $\mathrm{RH}$ refining.

Samples of $5 \mathrm{~mm} \times 10 \mathrm{~mm}$ are polished by inclusion A0, A120, A240, A360, A480, and A600 and then map scanning $\mathrm{Al}_{2} \mathrm{O}_{3}$. The morphology of inclusions is characterized by strips that are irregular, long, and angular, as shown in Figure 7. Most of the samples analyzed by map scanning of inclusions are nonmetallic inclusions, with $\mathrm{Al}_{2} \mathrm{O}_{3}$ being the main component. The size of A0 inclusion is larger in production practice, whereas the size of A600 inclusion decreases significantly in the later stage of $\mathrm{RH}$ circulation. This is because large sized inclusions are removed with the increase of $\mathrm{RH}$ circulation time. At the later stage of $\mathrm{RH}$ circulation, small size inclusions become the limiting factor of $\mathrm{RH}$ refining, which is consistent with the conclusion of numerical simulation.

\section{Conclusions}

(1) In the production of high-manganese and highaluminum steel by $\mathrm{RH}$, a mathematical model of inclusions removal is established, which lays a theoretical foundation for predicting removal of inclusions from liquid steel.

(2) Optimizing RH circulation flow rate and circulation time are effective for removing inclusions by numerical simulations. Compared with the RH circulation times of $120 \mathrm{~s}$ and $600 \mathrm{~s}$, the RH circulation time of $120 \mathrm{~s}$ has the highest removal efficiency. A $600 \mathrm{~s}$ circulation time makes the removal efficiency the lowest, and thus it is not recommended for application in production practice.

(3) The turbulence intensity of molten steel in RH fluid field is large, and there exists mixing phenomenon in the up-leg area of RH suction nozzle, which leads to 
"mixing" of inclusions into vacuum chamber or ladle, which affects the removal efficiency of inclusions. In the later stage of RH circulation, removal of small size inclusions becomes a limiting step in $\mathrm{RH}$ refining.

(4) Samples of high-manganese and high-aluminum steel produced by $\mathrm{RH}$ are taken for metallographic analysis every 120 seconds after the beginning of circulation time. The size of inclusion A0 is larger in the early stage of $\mathrm{RH}$ circulation, and its content decreases in the later stage of circulation.

(5) The mass concentration probability error of the mathematical model is $11.64 \%$, because the numerical simulation does not consider the problem of inclusions adsorbing to the refractory material walls and corrosion of refractories. This meets the technological requirements of producing high-manganese and high-aluminum steel by RH treatment.

\section{Data Availability}

The data used to support the findings of this study are included within the article.

\section{Conflicts of Interest}

The authors declare that there are no conflicts of interest regarding the publication of this paper.

\section{Acknowledgments}

The authors are grateful for the financial support by the National Key R\&D Project of China (2017YFC0805100), the Science and Technology Projects of Liaoning Province (2018307003), the Excellent Talent Project of University of Science Technology of Liaoning (2017RC01), and the project (SKLMEA-USTIN201903) supported by State Key Laboratory of Metallic Materials for Offshore Equipment and Applications.

\section{References}

[1] L. C. Trindade, J. J. M. Peixoto, C. A. da Silva et al., "Influence of obstruction at gas-injection nozzles (number and position) in RH degasser process," Metallurgical and Materials Transactions B, vol. 50, no. 1, pp. 578-584, 2019.

[2] W. Liu, S. Yang, J. Li, and H. Yang, "Numerical investigation of inclusion motion at molten steel-liquid slag interface during Ruhrstahl Heraeus (RH) process," JOM, vol. 70, no. 12, pp. 2877-2885, 2018.

[3] B. Han, R. Zhu, Y. Zhu et al., "Research on selective oxidation of carbon and aluminum with introduction of $\mathrm{CO}_{2}$ in $\mathrm{RH}$ refining of low-carbon steel process," Metallurgical and Materials Transactions B, vol. 49, no. 6, pp. 3544-3551, 2018.

[4] H. Ling and L. Zhang, "Investigation on the fluid flow and decarburization process in the RH process," Metallurgical and Materials Transactions B, vol. 49, no. 5, pp. 2709-2721, 2018.

[5] Y. H. Li, Y. P. Bao, R. Wang, L. F. Ma, and J. S. Liu, "Modeling study on the flow patterns of gas-liquid flow for fast decarburization during the $\mathrm{RH}$ process," International Journal of
Minerals Metallurgy and Materials, vol. 25, no. 2, pp. 153-163, 2018.

[6] G. Chen, S. He, and Y. Li, "Investigation of the air-argonsteel-slag flow in an industrial $\mathrm{RH}$ reactor with VOF-DPM coupled model," Metallurgical and Materials Transactions B, vol. 48, no. 4, pp. 2176-2186, 2017.

[7] D.-Q. Geng, J.-X. Zheng, K. Wang et al., "Simulation on decarburization and inclusion removal process in the Ruhrstahl-Heraeus (RH) process with ladle bottom blowing," Metallurgical and Materials Transactions B, vol. 46, no. 3, pp. 1484-1493, 2015.

[8] D.-Q. Geng, H. Lei, and J.-C. He, "Numerical simulation of the multiphase flow in the Rheinsahl-Heraeus (RH) system," Metallurgical and Materials Transactions B, vol. 41, no. 1, pp. 234-247, 2010.

[9] M. A. van Ende, Y. M. Kim, M. K. Cho, J. Choi, and I. H. Jung, "A kinetic model for the Ruhrstahl-Heraeus (RH) degassing process," Metallurgical and Materials Transactions B, vol. 42, no. 3, pp. 477-489, 2010.

[10] D. You, S. K. Michelic, C. Bernhard, D. Loder, and G. Wieser, "Modeling of inclusion formation during the solidification of steel," ISIJ International, vol. 56, no. 10, pp. 1770-1778, 2016.

[11] J.-H. Wei, N.-W. Yu, Y.-Y. Fan, S.-L. Yang, J.-C. Ma, and D.-P. Zhu, "Study on flow and mixing characteristics of molten steel in RH and RH-KTB refining processes," Journal of Shanghai University (English Edition), vol. 6, no. 2, pp. 167-175, 2002.

[12] C. Zhang, Y. Bao, D. Tang et al., "Effect of size of ferrotitanium on the melting behavior and the yield in the refining of interstitial free Steel by RH de-gasser," ISIJ International, vol. 58, no. 12, pp. 2262-2270, 2018.

[13] X. Chen, G. Cheng, J. Li, Y. Hou, J. Pan, and Q. Ruan, "Characteristics and formation mechanism of inclusions in 304L stainless steel during the VOD refining process," Metals, vol. 8, no. 12, pp. 1024-1031, 2018.

[14] S.-I. Chung, Y.-H. Shin, and J.-K. Yoon, "Flow characteristics by induction and gas stirring in ASEA-SKF ladle," ISIJ International, vol. 32, no. 12, pp. 1287-1296, 1992.

[15] G. Wang, Y. Xiao, C. Zhao, J. Li, and D. Shang, "Atomic cluster aggregates in nucleation of solid alumina inclusion in the aluminum deoxidation for liquid iron," Metallurgical and Materials Transactions B, vol. 49, no. 1, pp. 282-290, 2018.

[16] D.-Q. Geng, H. Lei, and J.-C. He, "Effect of traveling magnetic field on flow, mixing, decarburization and inclusion removal during RH refining process," ISIJ International, vol. 52, no. 6 , pp. 1036-1044, 2012.

[17] S.-G. Zheng and M.-Y. Zhu, "Modelling effect of circulation flow rate on inclusion removal in RH degasser," Journal of Iron and Steel Research International, vol. 23, no. 12, pp. 1243-1248, 2016.

[18] A. Huang, C. Ji, H. Z. Gu, C. H. Dai, and L. Zhong, "Numerical simulation of inclusion removal in tundish with babbling curtain and electromagnetic field," Journal of Iron and Steel Research, vol. 19, no. 12, pp. 162-166, 2012.

[19] J. Guo, S.-S. Cheng, H.-J. Guo, and Y.-G. Mei, "Novel mechanism for the modification of $\mathrm{Al}_{2} \mathrm{O}_{3}$-based inclusions in ultra-low carbon Al-killed steel considering the effects of magnesium and calcium," International Journal of Minerals, Metallurgy, and Materials, vol. 25, no. 3, pp. 280-287, 2018.

[20] M. I. Epov, E. P. Shurina, and M. K. Artem'ev, "Numerical homogenization of electric characteristics of media with contrast small-scale inclusions," Doklady Earth Sciences, vol. 442, no. 1, pp. 97-99, 2012. 
[21] L.-F. Guo, H. Li, H.-T. Ling, Y. Wang, and W.-C. Song, "Numerical simulation of fractal agglomerating-growth of $\mathrm{Al}_{2} \mathrm{O}_{3}$ inclusions in tundish," Journal of Iron and Steel Research International, vol. 20, no. 11, pp. 7-12, 2013.

[22] R. Tsujino, J. Nakashima, M. Hirai, and I. Sawada, "Numerical analysis of molten steel flow in ladle of RH process," ISIJ International, vol. 29, no. 7, pp. 589-595, 1989. 


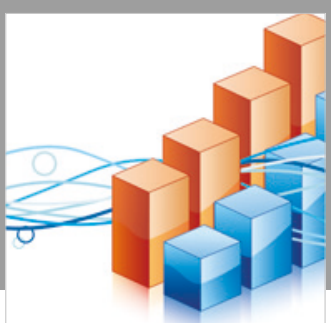

Advances in

Operations Research

\section{-n-m}
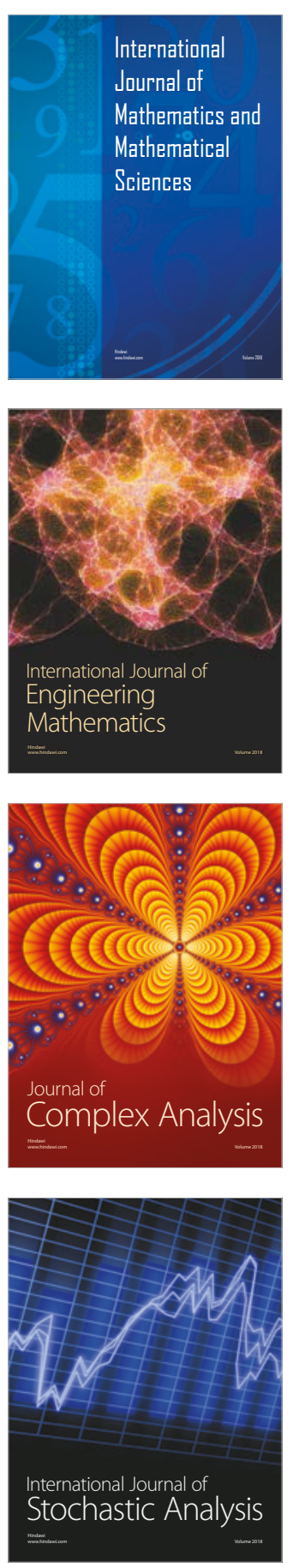
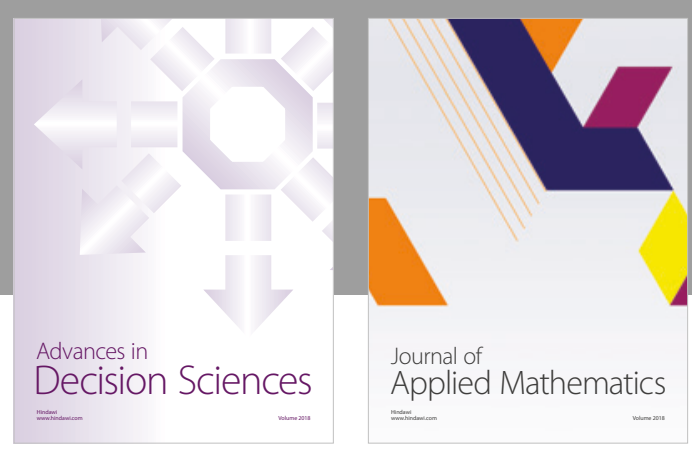

Journal of

Applied Mathematics
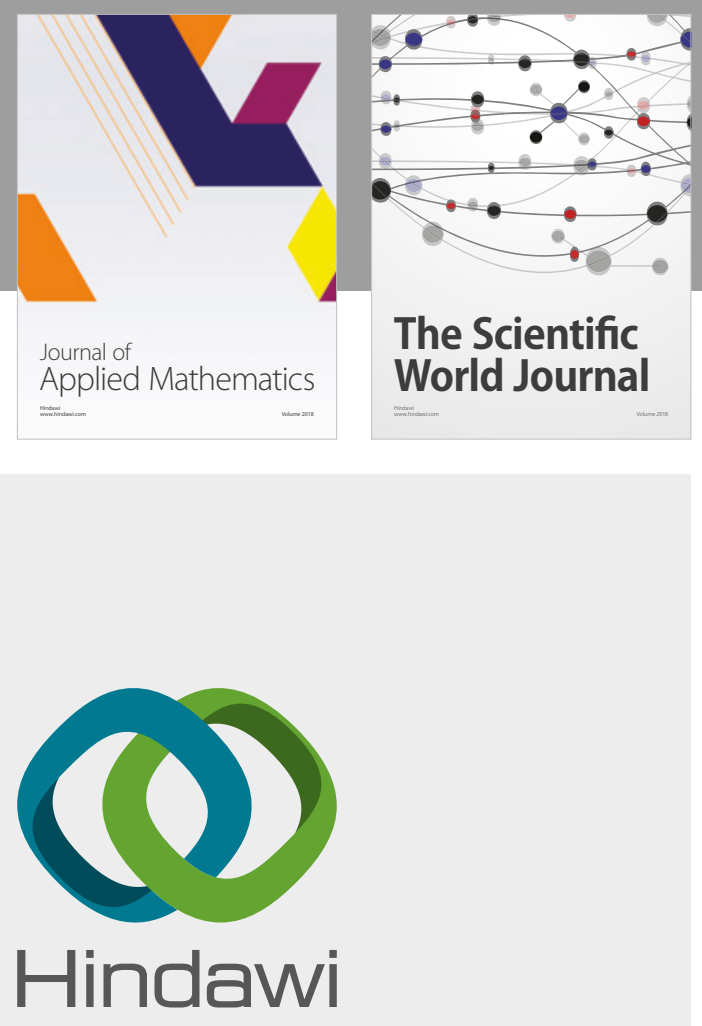

Submit your manuscripts at

www.hindawi.com

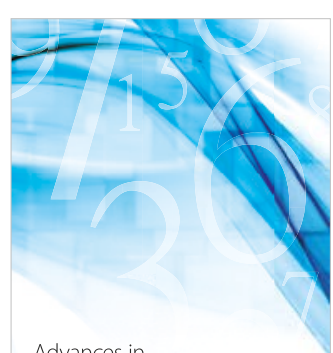

Advances in
Numerical Analysis
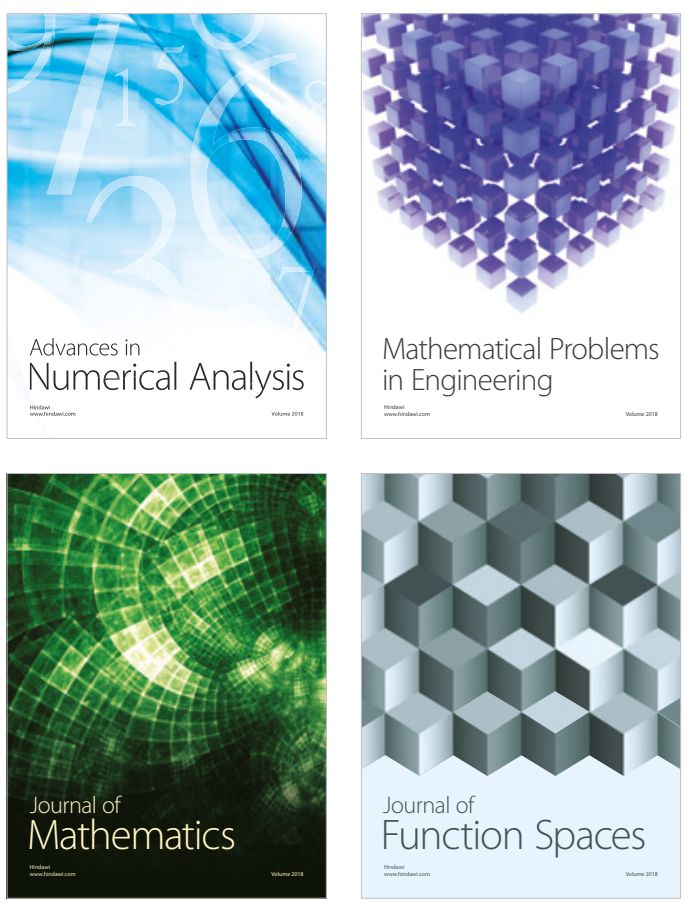

Mathematical Problems in Engineering

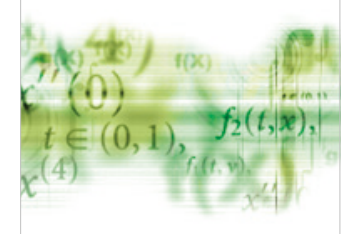

International Journal of

Differential Equations

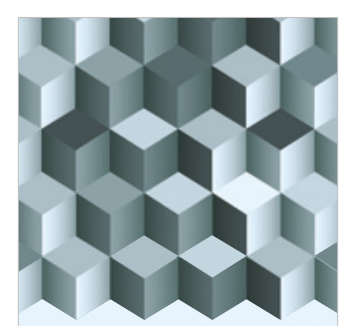

Journal of

Function Spaces

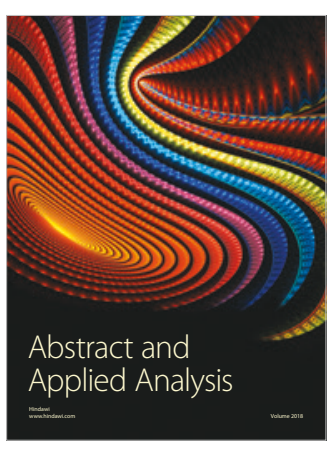

The Scientific

World Journal

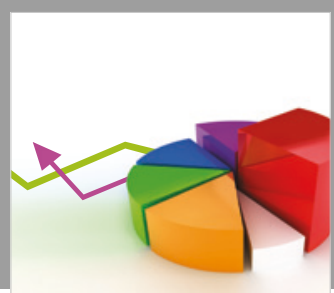

Journal of

Probability and Statistics
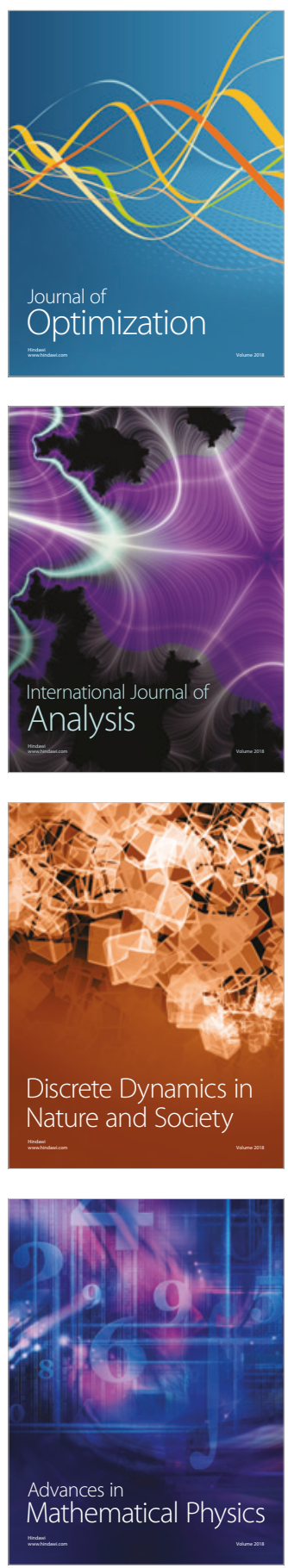